\title{
Modelo de Mudanças Climáticas com Gastos Públicos*
}

Pedro Erik Arruda Carneiro**

\section{Introdução}

Para lidar com a mudança climática, geralmente é dito que os governos dispõem de dois tipos de instrumentos: multar quem não segue os princípios ambientalmente responsáveis e incentivar aqueles que os seguem. As seguintes políticas públicas são discutidas: impostos sobre emissão de gases de efeito estufa; subsídios para diminuição de emissão; cotas de emissão e negociação das mesmas; e es-

\footnotetext{
*Artigo recebido em janeiro e aprovado para publicação em maio de 2007. O autor gostaria de agradecer aos relevantes comentários dos pareceristas anônimos e de ressaltar que as opiniões aqui expressas são exclusivamente dele, não refletindo a posição da instituição a que ele se vincula.

**Doutor em Relações Internacionais pela Universidade de Brasília (UnB) e coordenador de Assuntos Econômicos da Secretaria de Assuntos Internacionais do Ministério da Fazenda. E-mail: pedro.erik@ fazenda.gov.br.
} 
tabelecimento de performance-padrão, além de incentivos para mudança tecnológica na produção que reduza ou elimine a emissão daqueles gases.

Aqui, argumento que se tem abandonado um método mais elementar para lidar com mudança climática: os gastos públicos, especialmente aquelas despesas públicas para melhoria das condições do meio ambiente, que envolvem desde o saneamento básico até a educação ambiental, passando, é claro, pela preservação das matas nativas. Observando o caso brasileiro, o fato de apenas $0,3 \%$ da despesa liquidada do orçamento federal, em média no período de 2000 a 2006, excluindo refinanciamento, estar alocada na função Gestão Ambiental é por si só motivo de preocupação, dadas as carências, a profundidade e a diversidade do meio ambiente no país.

Há diversos aspectos a serem considerados na decisão para adoção de política para mudança climática em termos domésticos. Goulder e Pizer (2006) consideram que se deve observar as incertezas relativas ao custo (substituição da produção intensiva em energia), às interações fiscais (modificação do sistema tributário para incluir controle de emissão), à distribuição do custo entre contribuintes e ao desenvolvimento da tecnologia. Os autores destacam ainda que os efeitos da mudança climática são um problema eminentemente internacional. Nesse sentido, há necessidade de uma coordenação internacional para gerenciar a emissão de gases de efeito estufa.

O Protocolo de Quioto estabeleceu os mecanismos internacionais de comércio de emissões, desenvolvimento limpo e implementação conjunta. Mas há outras possibilidades. William Nordhaus, o precursor em discutir a mudança climática com seu texto "How fast should we graze the global commons?" (NORDHAUS, 1982), advogou, em "Life after Kyoto" (NORDHAUS, 2005), uma tributação global em contraponto aos mecanismos do Protocolo. Todos os países usariam um tributo comum sobre as emissões de carbono e manteriam a recei- 
Modelo de Mudanças Climáticas com Gastos Públicos

ta. Em paralelo, os países muito pobres não teriam tributo. Argumenta-se que a idéia uniformizaria o custo marginal do carbono, mudaria as estruturas tributárias de alguns países e reduziria as possibilidades de corrupção nos mecanismos do Protocolo. O grande problema é que deixaria o nível de emissão incerto, enfrentando resistência de ambientalistas. Os economistas Don Fullerton e Robert Stavins (1998, p. 433), observando que há certa tendência de uso de instrumentos de mercado para solução de questões ambientais, defendem a abordagem interdisciplinar:

Em um assunto como o de meio ambiente, a comunicação entre diferentes disciplinas, que pertencem desde às ciências naturais até as ciências sociais, é tão importante como difícil. Economistas podem ter contribuído para alguns mal-entendidos sobre o que eles pensam no que se refere ao meio ambiente, talvez por entusiasmo por soluções de mercado, ou por negligenciar todas as necessárias qualificações, ou simplesmente pelo uso de jargão. ${ }^{1}$

Quando se analisam as questões de política pública e mudança climática na literatura econômica, em geral são encontrados artigos que tratam do protocolo de Quioto e/ou de métodos alternativos, especialmente tributários, como o texto de Nordhaus (2005), citado anteriormente. Também se pode identificar muitos artigos que usam teoria dos jogos para explicar o dilema da coordenação internacional no tratamento dos efeitos da mudança climática, como em Lange e Vogt (2003). No entanto, não identifiquei nenhum artigo na literatura econômica internacional que relacionasse, em forma de modelo, painel econométrico ou teoria dos jogos, gasto público em gestão ambiental com efeitos da mudança climática, ou mesmo efeito do deficit público sobre a gestão ambiental ou sobre o controle da emissão de gases de efeito estufa.

Neste trabalho, ressalto a necessidade de se avaliar a ação dos governos na gestão ambiental, para se considerar os métodos e resultados 
das medidas de controle de emissão de gases que provocam mudança climática. Discuto, inicialmente, o modelo de Kemfert, Lise e Tol (2004), pois é relevante no sentido de tentar agregar preocupação com impactos na economia da redução de emissão desses gases. Nesse modelo, é analisado o efeito dos termos de troca sobre a redução de emissão daqueles gases. Observa-se que as variações nos preços dos bens intensivos em energia afetam os termos de troca, e esse impacto é considerado nas políticas de redução de emissão.

Em seguida, apresento as diferenças de matrizes energéticas e de impacto ambiental entre os países, para mostrar que a realidade difere bastante nos países, fazendo a generalização de argumentos muito difícil em modelos quando se trata de problemas relativos à mudança climática.

No item 4, usando como fonte o Relatório Resumido da Execução Orçamentária do Governo Federal brasileiro (SECRETARIA DO TESOURO NACIONAL, dez. 2006), analiso os gastos públicos da União para o meio ambiente. Considero a alocação de recursos para o Ministério do Meio Ambiente (MMA) e para a função e subfunções da Gestão Ambiental. A preocupação, nessa análise do caso brasileiro, é mostrar as diversas possibilidades de ação dos governos para reduzir as emissões de gases poluentes e, ao mesmo tempo, apresentar como o Brasil tem usado seu orçamento para dirimir os impactos antropogênicos (provocados pelo homem) nocivos ao meio ambiente.

Ao fim, no item 5, tento considerar o uso dos gastos públicos em modelos de mudança climática, com todas as dificuldades trazidas pelas diferenças na estrutura física e econômica dos países e pela diversidade dos gastos públicos.

\section{Modelo de Redução de Emissão e Termos de Troca}

Aqui, apresento o modelo de Kemfert, Lise e Tol (2004), que combina redução da emissão de gases de efeito estufa com comércio inter- 
Modelo de Mudanças Climáticas com Gastos Públicos

nacional. Além de exibir uma abordagem com poder de análise, o modelo servirá para mostrar as dificuldades de estudos que tentam reunir mudança climática com questões econômicas. Na seção 5, procuro agregar, nesse de tipo de estudo, os gastos públicos com gestão ambiental e a matriz energética.

O modelo permite uma análise concentrada dos problemas e demonstra as inter-relações que envolvem as questões da mudança climática. Não temos a mesma exigência de Leonardo da Vinci (COLEÇÃO FOLHA, 2007, p. 22), que disse: Non mi legga chi non è matemático ("Não me leia quem não for matemático"). Pelo contrário, tentaremos explicar de forma clara as condições e objetivos do modelo para que a possível dificuldade com os símbolos matemáticos seja superada.

Kemfert, Lise e Tol (2004) corretamente consideram equivocada a idéia de que a redução dos gases de efeito estufa em um país seja um bem privado, enquanto a atmosfera é um bem público. A redução destes gases em um país afeta outros países de várias maneiras e não apenas pela mudança climática. Há impactos no comércio internacional, nos investimentos, no vazamento de carbono, na produção energética, no desenvolvimento tecnológico e na difusão dessa tecnologia. Na medida em que tem efeitos nos preços domésticos de energia e de bens intensivos em energia, a redução de emissão provoca alterações nos termos de troca e, em termos gerais, tem efeito sobre o crescimento da economia.

Os três autores têm como foco principal observar como os termos de troca alteram a redução ótima de emissão e incentivam a cooperação internacional. O modelo considera dois países $i$ e $j$, sendo $i \neq j$, com $C_{i}$ sendo o custo da redução de emissão de gases da mudança climática no país $i$.

Kemfert, Lise e Tol (2004) definem: 
$\frac{C_{i}}{Y_{i}}=\frac{C_{i}\left(R_{i}, R_{i}, C_{i}\right)}{Y_{i}}=f\left(R_{i}\right)+g_{i}\left(R_{i}-R_{i}\right)+h_{i}\left(C_{i}\right)$

Em que $R$ representa a redução de emissão de gases de efeito estufa (como uma fração de emissões não controladas sem vazamento) e $Y$, o Produto Interno Bruto (PIB). A função Custo de Redução de Emissão depende de três componentes: o custo doméstico de redução $f($.), o custo associado com a diferença de redução entre os dois países $g($.), e o custo da redução de emissão de um país sobre o outro $h($.).

A função $g($.) inclui os efeitos relativos do comércio e investimento entre os países, que são os efeitos nos termos de troca. Estes efeitos são relacionados aos preços domésticos de energia e à produção de bens intensivos em energia, que diferem entre os países com diferentes regulamentações. A função $h($.) observa todos os outros efeitos, inclusive o efeito de magnitude (size effects), que mostra o impacto da queda no crescimento da economia do outro país provocado pela redução de emissão. Nesse sentido, $g($.) e $h($. ) capturam os chamados efeitos de transbordamento (spillovers effects) e $f($.) os efeitos internos. Há de se considerar que:

$f_{i}(0)=0, x \rightarrow f_{i}(x) \mp 0, \frac{\partial f_{i}}{\partial x^{2}} \mathrm{f} 0$

$g_{i}(0)=0, x \mathrm{f} 0 \rightarrow g_{i}(x) \mathrm{f} 0, x \mathrm{p} 0 \rightarrow g_{i}(x) \mathrm{p} o, \frac{\partial g_{i}}{\partial x} \mathrm{f} 0$

$h_{i}(0)=0, x \mathrm{f} 0 \rightarrow h_{i}(x) \mp 0, \frac{\partial h_{i}}{\partial x} \mathrm{f} 0$

A equação 2 nos diz que os custos domésticos são positivos e crescentes em relação à redução de emissão. Já a equação 3 mostra que, se os países reduzem as emissões no mesmo volume, não há custos adicionais ou benefícios para os países, mas se, por exemplo, o país $i$ 
afetar mais a sua matriz energética usando medidas para reduzir a emissão de gases, obterá perdas nos termos de troca com $j$. Nesse sentido, mesmo que o país não pratique nenhuma medida de redução de emissão, ele é afetado pela política de combate aos efeitos de mudança climática do outro país. O termo 4 nos diz que, se o país $i$, por exemplo, tiver custo positivo de redução de emissão, provocará custos para $j$, por meio de, por exemplo, menor exportação de $j$ para $i$.

No modelo, o nível de emissão é dado pela seguinte equação:

$E_{i}^{R}=\left(1-R_{i}\right) E_{i}+k_{i}\left(R_{i}-R_{i}\right) E_{i}$

Na qual $E_{\mathrm{i}}^{\mathrm{R}}$ é o nível de emissão real que depende de $R$ e de $E_{i}$, sendo $E_{i}$ o nível de emissão sem nenhuma política de redução. Há também uma troca de emissão de gases dada por $k($.). Se o país $i$ reduz mais que $j$, então o nível de emissão aumenta em $j$. Por isso:

$k_{i}(0)=0, x \mathrm{f} 0 \rightarrow k_{i}(x) \mathrm{£} 0, x \mathrm{p} 0 \rightarrow k_{i}(x) \mathrm{p} o, \frac{\partial k_{i}}{\partial x} \mathrm{f} 0$

Os benefícios, $B$, da redução de emissão são dados pelo volume de emissão, sendo $B$ estritamente crescente pelo total de emissão da função $l_{i}($.$) :$

$B_{i}=l_{i}\left(E_{i}+E_{i}\right)-l_{i}\left(E_{i}^{R}+E_{i}^{R}\right)$

O problema de otimização é minimizar o custo líquido $C_{i}-B_{i}$, em que a redução de emissão, $R$, é a única variável de controle. O resultado do modelo é:

$$
\frac{\partial f_{i}}{\partial R_{i}}+\frac{\partial g_{i}}{\partial R_{i}}-\left(\frac{\partial h_{i}}{\partial C_{i}} \frac{\partial g_{i}}{\partial R_{i}}\right) / 1-\frac{\partial h_{i}}{\partial C_{i}} \frac{\partial h_{i}}{\partial C_{i}}=E_{i} \frac{\partial l_{i}}{\partial R_{i}}+\frac{\partial l_{i}}{\partial R_{i}}\left(E_{i} \frac{\partial k_{i}}{\partial R_{i}}-E_{i} \frac{\partial k_{i}}{\partial R_{i}}\right)
$$


Em (8), o custo marginal por redução está do lado esquerdo e o benefício marginal do lado direito. O modelo considera que o último termo do lado direito se cancela, pois, para o modelo, o vazamento de emissão de um país diminui a emissão do outro. Sendo assim, temos:

$$
\frac{\partial f_{i}}{\partial R_{i}}+\frac{\partial g_{i}}{\partial R_{i}}-\left(\frac{\partial h_{i}}{\partial C_{j}} \frac{\partial g_{j}}{\partial R_{i}}\right) / \underbrace{}_{1-\frac{\partial h_{i}}{\partial C_{j}} \frac{\partial h_{j}}{\partial C_{i}}}=E_{i} \frac{\partial l_{i}}{\partial R_{i}}
$$

Kemfert, Lise e Tol (2004), com o resultado da otimização, passam a considerar alguns casos para análise: 1) a observação apenas dos efeitos da redução de emissão nos termos de troca, sem size effects, isto é, usando $h=0 ; 2)$ a não-observação dos efeitos nos termos de troca $(g$ $=0$ ); e 3 ) a consideração do impacto no termos de troca e também dos size effects.

No caso 1, temos:

$\frac{\partial f_{i}}{\partial R_{i}}+\frac{\partial g_{i}}{\partial R_{i}}=E_{i} \frac{\partial l_{i}}{\partial R_{i}}$

Para o caso acima, como $\frac{\partial g_{i}}{\partial R_{i}} \mathrm{f} 0$, a redução de emissão ótima é menor se considerarmos os efeitos sobre os termos de troca. Em outras palavras, a decisão de se ter uma política de redução de emissão para evitar a mudança climática observará os efeitos negativos sobre os termos de troca, especialmente dos preços intensivos em energia, e estipulará uma redução ótima menor. Esse resultado mostra as limitações mais básicas de políticas de redução de emissão.

No caso 2, com $g=0$, temos: 


$$
\left(\frac{\partial f_{i}}{\partial R_{i}}\right) /\left(1-\frac{\partial h_{i}}{\partial C_{j}} \frac{\partial h_{j}}{\partial C_{i}}\right)=E_{i} \frac{\partial l_{i}}{\partial R_{i}}
$$

O resultado do modelo para este caso é que não há alteração na redução ótima de emissão, pois, observando os size effetcts, as derivadas parciais com relação a $C$ não são sensíveis a $R$. Mesmo que na realidade possamos considerar que há efeitos do volume de redução de emissão na economia global e, por isso, estes efeitos deveriam ser levados em consideração na decisão de se reduzir as emissões de gases de efeito estufa, o modelo é limitado e não observa esse resultado, no caso em que $g=0$.

Finalmente, para o caso 3, em que levamos em consideração tanto os size effects, como os efeitos nos termos de troca, estes últimos continuam, como no caso 1, diminuindo a redução ótima de emissão, mas os size effects não são mais neutros, por causa do terceiro termo da equação (9). Kemfert et al. (2004), no entanto, têm dificuldade de analisar o resultado, considerando, para esse caso, apenas uma solução que estipula que os países são similares em $g$, isto é $g_{i}=g_{j}$, e encontram:

$$
\left(\frac{\partial f_{i}}{\partial R_{i}}+\frac{\partial g_{i}}{\partial R_{i}}\left[1-\frac{\partial h_{i}}{\partial C_{i}}\right]\right) /\left(1-\frac{\partial h_{i}}{\partial C_{j}} \frac{\partial h_{j}}{\partial C_{i}}\right)=E_{i} \frac{\partial l_{i}}{\partial R_{i}}
$$

Nessa hipótese, o que importa é saber se $\frac{\partial h_{i}}{\partial C_{j}}$ é maior ou menor que 1. Se for menor que 1 , tanto os efeitos nos termos de troca como os size effects atuam diminuindo a redução ótima, embora seja uma me- 
nor diminuição do que a encontrada no caso 1 . Se $\frac{\partial h_{i}}{\partial C_{j}}$ for maior que 1, então teremos uma maior redução ótima de emissão, o que seria um contra-senso. Como resultado geral, temos um modelo ambíguo. Kemfert et al. (2004, p. 214-215) argumentam:

Então, baseados apenas em um modelo formal, não é possível dizer se os efeitos de transbordamento levarão a maior ou menor redução de emissão, maiores ou menores custos de redução e, assim, se os efeitos sobre o comércio irão ajudar ou prejudicar a cooperação. A resposta depende da força relativa dos vários efeitos.

Apesar de apresentar resultados modestos, o modelo de Kemfert, Lise e Tol (2004) aborda questões relevantes sobre como os países reagem ao problema da mudança climática global. Há preocupações comerciais e tecnológicas que afetam as medidas de redução de emissão. Na seção 5, volto à análise desse modelo, tentando observar como os gastos públicos poderiam ser considerados nas equações.

\section{Diferentes Sociedades, Matrizes Energéticas e Impacto Ambiental}

Como, no final deste artigo, pretendo observar de que forma se daria a inclusão dos gastos públicos com gestão ambiental e da matriz energética em modelos de mudança climática, nesta seção, o objetivo é apresentar as diferentes formas de impacto ambiental e as diferenças entre as matrizes energéticas dos países, para cimentar a argumentação de que os gastos públicos com gestão ambiental atuam sobre diferentes perspectivas no mundo. Na próxima seção, daremos uma idéia desses gastos públicos, observando o caso brasileiro. 
Modelo de Mudanças Climáticas com Gastos Públicos

Quando observamos o caso brasileiro, inicialmente nos orgulhamos pelo fato de o Brasil estar entre os cinco países com maior biodiversidade do mundo, a Mata Atlântica abrigar um quarto das espécies de plantas conhecidas no planeta, o Cerrado ser a savana mais rica entre todas existentes, o Pantanal a maior planície inundável do planeta e a Floresta Amazônica a maior floresta tropical remanescente em todo o globo, detentora de $10 \%$ da água doce disponível no mundo (IBAMA, 2002). Temos, assim, comparativamente ao restante dos países, uma base ecológica bem forte.

No entanto, como fatores de risco de um possível colapso ambiental brasileiro, temos danos ambientais antropogênicos, efeitos da mudança climática global e falha de resposta da sociedade aos danos ambientais em curso no Brasil.

Diamond (2005) estudou diversas sociedades do passado (habitantes da Ilha de Páscoa, da Groenlândia nórdica, das tribos anasazis do oeste norte-americano e os maias, do México) e do presente (Ruanda, Austrália, China, Japão e Haiti) para observar o efeito do meio ambiente sobre o colapso das sociedades antigas e sobre o possível colapso das sociedades contemporâneas. $\mathrm{O}$ autor considerou cinco fatores para diagnosticar um colapso ambiental de uma sociedade: 1) dano ambiental provocado pelo homem (importante em todas as sociedades analisadas); 2) mudança climática (especialmente relevante para a Groenlândia nórdica); 3) vizinhança hostil (relevante para as tribos maias e anasazis); 4) presença ou falta de parceiros comerciais (o isolamento teve importante efeito na Ilha de Páscoa); e 5) presença ou falta de resposta adequada da sociedade aos sinais de danos ambientais (relevante em todas as sociedades consideradas).

Ainda segundo Diamond (2005), os processos ambientais em que as sociedades do passado e do presente minaram a si mesmas são doze: 1) desmatamento; 2) destruição do habitat; 3) problemas com o solo (erosão, salinização, perda de fertilidade); 4) problemas com o con- 
trole de água; 5) sobrecaça; 6) sobrepesca; 7) introdução de espécies estranhas ao meio ambiente nativo; 8) crescimento demográfico; 9) mudanças climáticas provocadas pelo homem; 10) acúmulo de produtos químicos tóxicos no meio ambiente; 11) carência de fontes de energia; e 12) utilização total da capacidade fotossintética. A importância de cada processo sobre cada sociedade varia bastante.

Entre os doze processos destruidores considerados, o Brasil não sofre com carência de fontes de energia, mas apresenta, variando de região para região no território nacional, todos os outros processos ambientais.

O Instituto Brasileiro de Geografia e Estatística (IBGE, 2005), na Pesquisa de informações básicas municipais. Perfil dos municípios brasileiros. Suplemento Meio Ambiente 2002, fez uma análise completa da gestão ambiental no Brasil traçando desde os problemas mais recorrentes nos municípios do país até a estrutura institucional destinada às soluções destes problemas. Essa pesquisa mostrou que, dos 5.560 municípios brasileiros investigados, 2.263 (41\%) informaram ocorrência de alteração ambiental que tenha afetado as condições de vida da população.

Os impactos ambientais mais informados pelos municípios foram: a presença de esgoto a céu aberto (apontado por 1.031 municípios $46 \%$ do total), seguido do desmatamento (1.009 - 45\%), queimadas $(948-42 \%)$ e presença de vetor de doença, como mosquitos, ratos, barbeiros, caramujos etc. $(896-40 \%)$.

Entre os resultados dos impactos mais freqüentes, o problema ambiental informado pelo maior número de municípios foi assoreamento de corpo d'água (53\%), seguido de poluição do recurso água (38\%), alteração da paisagem (35\%), contaminação do solo (33\%), poluição do ar (22\%) e, finalmente, degradação de áreas protegidas (20\%). 
Modelo de Mudanças Climáticas com Gastos Públicos

Além disso, o Brasil apresenta, corriqueiramente, vários tipos de desastres ambientais, como deslizamentos de terra, vazamentos de materiais químicos ou tóxicos, erosão, eutrofização (inclusão, na água dos rios e lagos, de nutrientes provenientes de fertilizantes, lixo orgânico, esgotos domésticos ou rejeitos industriais que reduzem o oxigênio provocando perda de espécies naturais) e comércio ilegal de fauna e flora.

Observando todo o marco legal e institucional brasileiro, o relatório "Geo Brasil 2002" (IBAMA, 2002), do Instituto Brasileiro do Meio Ambiente e dos Recursos Naturais Renováveis (IBAMA), argumenta que a legislação ambiental e sobre recursos naturais, conquanto bastante desenvolvida, necessita que se compatibilizem as normas entre si, uma vez que existem leis específicas, sobre um mesmo tema, que se contradizem. Apesar de toda a cultura ecológica criada nos últimos trinta anos, o meio ambiente continua sendo tratado como um tema setorial e fragmentado. As instituições responsáveis pelo meio ambiente têm muito pouco controle sobre os problemas concretos gerados pelas políticas públicas setoriais de práticas agrícolas, industriais, de desenvolvimento urbano, exploração mineral, recursos florestais e obras de infra-estrutura em geral. As práticas de gestão ambiental muitas vezes se restringem a reparação de danos.

Em muitos outros países, os problemas ambientais são uma constante. Um caso bem explícito é o da China. O texto "China economy: a dirty dragon?" (CHINA..., 2007), da revista The Economist Intelligence Unit, argumenta que se pode até ser simpático à posição chinesa de não ter metas no Protocolo de Quioto, uma vez que historicamente os países desenvolvidos foram os mais poluidores, mas a China não poderá ficar sem fazer nada, dado os efeitos avassaladores da mudança climática sobre o país:

Os problemas ambientais da China estão já entre os mais sérios do mundo: dezesseis das vinte cidades mais poluídas no mundo estão na 
China, e mais de $90 \%$ da água na superfície e $70 \%$ dos rios e lagos na China estão contaminados. Além disso, a China provavelmente sofrerá bastante com o aquecimento global. De acordo com o IPCC [Intergovernmental Panel on Climate Change; em português, Painel Intergovernamental sobre Mudança Climática], o aquecimento global provocará secas mais longas no norte do país, gerando queda na produção agrícola, enquanto no sul o aquecimento deve provocar chuvas mais pesadas, gerando inundação e perdas econômicas. Ademais, a elevação do nível dos mares representará uma grande ameaça para as importantes e ricas cidades costeiras chinesas (CHINA..., 2007, tradução nossa).

Sobre o impacto ambiental da matriz energética no futuro, há questões sobre a capacidade de o meio ambiente absorver a demanda crescente de energia mundial, uma vez que há dificuldades de adoção de alternativas tecnológicas de energia e alto grau de dependência do uso de combustível fóssil (carvão mineral, petróleo ou gás natural), que é não renovável e provoca emissão de gases nocivos ao planeta. Entre os países, há bastantes diferenças no consumo de energia. Mesmo sob um olhar mais abrangente, por região, há ainda grandes disparidades entre o nível de consumo e o uso de fontes, como mostra o Quadro 1.

No Quadro 2, temos uma descrição de como está o consumo de energia entre o chamado BRIC (Brasil, Rússia, Índia e China), Estados Unidos, Alemanha e Japão. Podemos observar diferenças entre tais países, com o consumo de combustíveis fósseis poluentes sendo ainda muito relevante, com destaque para os Estados Unidos (refino de petróleo), China (carvão mineral) e Rússia (gás natural).

A Alemanha representa o maior mercado de consumo de energia na Europa Ocidental. O Brasil é um dos maiores produtores de energia 
Modelo de Mudanças Climáticas com Gastos

Públicos

\section{Quadro 1}

Porcentagem de Consumo Mundial por Fonte - 2006

\begin{tabular}{lrrrr}
\hline Região & Petróleo & Carvão & Gás Natural & Consumo Total (a) \\
\hline América Latina & $7,5 \%$ & $0,9 \%$ & $7,7 \%$ & $\mathbf{6 , 0} \%$ \\
América do Norte & $30,3 \%$ & $17,5 \%$ & $27,9 \%$ & $\mathbf{2 6 , 9 \%}$ \\
Japão & $7,1 \%$ & $3,2 \%$ & $3,4 \%$ & $\mathbf{5 , 4 \%}$ \\
Europa Ocidental & $18,6 \%$ & $9,1 \%$ & $19,3 \%$ & $\mathbf{1 6 , 8 \%}$ \\
Ásia e Australásia & $25,5 \%$ & $55,6 \%$ & $12,8 \%$ & $\mathbf{2 9 , 4 \%}$ \\
Oriente Médio e África & $4,9 \%$ & $3,6 \%$ & $4,5 \%$ & $\mathbf{3 , 8 \%}$ \\
Economias em Transição & $6,1 \%$ & $10,3 \%$ & $24,6 \%$ & $\mathbf{1 1 , 7 \%}$ \\
\hline
\end{tabular}

(a) Considerando-se sessenta países.

Fonte: World... (2007).

\section{Quadro 2}

Consumo de Energia - 2005

\begin{tabular}{|c|c|c|c|c|c|c|c|}
\hline Consumo de Energia & Alemanha & Brasil & China & EUA & Índia & Japão & Rússia \\
\hline $\begin{array}{l}\text { Consumo de Energia ( } m \text { ton } \\
\text { petróleo equivalente) }\end{array}$ & 347,0 & 232,0 & $1.432,0$ & $2.535,0$ & 382,0 & 574,0 & 763,0 \\
\hline $\begin{array}{l}\text { Consumo Energia (kg petróleo } \\
\text { equivalente per head) }\end{array}$ & $4.201,0$ & $1.276,0$ & $1.095,0$ & $8.574,0$ & 349,0 & $4.501,0$ & $5.318,0$ \\
\hline Consumo Eletricidade (bn kwh) & 523,0 & 381,0 & $2.368,0$ & $3.820,0$ & 584,0 & $1.024,0$ & 933,0 \\
\hline $\begin{array}{l}\text { Consumo Eletricidade (kwh per } \\
\text { head) }\end{array}$ & $6.337,0$ & $2.102,0$ & $1.811,0$ & $12.916,0$ & 533,0 & $8.034,0$ & $6.503,0$ \\
\hline Consumo Petróleo ('000 b/d) & $2.650,0$ & $2.237,0$ & $7.153,0$ & $20.370,0$ & $2.537,0$ & $5.293,0$ & $2.776,0$ \\
\hline $\begin{array}{l}\text { Consumo Carvão ( } m \text { metric } \\
\text { tonnes) }\end{array}$ & 248,0 & 21,0 & $1.957,0$ & 993,0 & 432,0 & 172,0 & 232,0 \\
\hline $\begin{array}{l}\text { Consumo Produtos Petróleo } \\
\text { Refinado ('000 b/d) }\end{array}$ & $2.690,0$ & $2.366,0$ & $8.020,0$ & $19.981,0$ & $2.510,0$ & $5.476,0$ & n.d. \\
\hline $\begin{array}{l}\text { Consumo de Gás Natural (bn cu } \\
\text { metros) }\end{array}$ & 94,6 & 22,0 & 40,3 & 627,7 & 30,6 & 78,3 & 447,0 \\
\hline
\end{tabular}

Fontes: Brazil... (2005), China... (2005), Germany... (2006), India... (2006), Japan... (2005), Russia... (2005) e USA... (2006).

por meio de hidrelétricas e tem reservas substanciais de petróleo e gás, além de ser o segundo maior produtor de etanol no mundo (perdeu a posição de maior produtor para os Estados Unidos em 2005). A fonte de energia que mais cresce atualmente no Brasilé a de gás natural. A China é o país que mais consume e produz carvão mineral 
(combustível fóssil que mais emite dióxido de carbono), além de representar a maior produção em energia hidrelétrica e o maior consumo de petróleo. Os Estados Unidos são o maior produtor, consumidor e importador líquido de energia do mundo. Estão em primeiro lugar nas reservas de carvão, em décimo primeiro em petróleo e em quinto lugar em gás natural. O Japão também é um dos maiores consumidores de energia no mundo. A Rússia é a maior produtora de petróleo mundial. Além disso, a sua produção de gás fornece um quarto do consumo da Europa Ocidental. Das exportações russas, mais de $60 \%$ são de petróleo, óleo e gás. A Índia é um dos países no mundo cuja demanda por energia tem mais crescido entre os países emergentes, atrás apenas da China. O petróleo é responsável por $30 \%$ do consumo de energia da Índia.

Em comparação com outros países, o Brasil tem uma matriz energética com alta oferta de recursos renováveis. Segundo o Balanço Energético de 2005 (MINISTÉRIO DE MINAS E ENERGIA, 2006), 44,7\% da oferta de energia no Brasil é de fonte renovável -

\section{Quadro 3}

Oferta Interna de Energia no Brasil - \%

\begin{tabular}{lcccccc}
\hline Fontes & $\mathbf{1 9 7 0}$ & $\mathbf{1 9 8 0}$ & $\mathbf{1 9 9 0}$ & $\mathbf{2 0 0 0}$ & $\mathbf{2 0 0 4}$ & $\mathbf{2 0 0 5}$ \\
\hline Total - 106 tep & 66,9 & 114,8 & 142,0 & 190,6 & 213,4 & 218,6 \\
Não Renováveis & $\mathbf{4 1 , 6}$ & $\mathbf{5 4 , 4}$ & $\mathbf{5 0 , 9}$ & $\mathbf{5 9 , 0}$ & $\mathbf{5 6 , 1}$ & $\mathbf{5 5 , 3}$ \\
Petróleo e Derivados & 37,7 & $\mathbf{4 8 , 3}$ & 40,7 & 45,5 & 39,1 & 38,4 \\
Gás Natural & 0,3 & 1,0 & 3,1 & 5,4 & 8,9 & 9,3 \\
Carvão Mineral e Derivados & 3,6 & 5,1 & 6,8 & 7,1 & 6,7 & 6,4 \\
Urânio e Outras & 0,0 & 0,0 & 0,4 & 0,9 & 1,5 & 1,2 \\
Renováveis & $\mathbf{5 8 , 4}$ & $\mathbf{4 5 , 6}$ & $\mathbf{4 9 , 1}$ & $\mathbf{4 1 , 0}$ & $\mathbf{4 3 , 9}$ & $\mathbf{4 4 , 7}$ \\
Hidráulica e Eletricidade & 5,1 & 9,6 & 14,1 & 15,7 & 14,4 & 15,0 \\
Lenha e Carvão Vegetal & 47,6 & 27,1 & 20,1 & 12,1 & 13,2 & 13,1 \\
Produtos da Cana & 5,4 & 8,0 & 13,4 & 10,9 & 13,5 & 13,9 \\
Outras & 0,3 & 0,9 & 1,5 & 2,3 & 2,7 & 2,7 \\
\hline
\end{tabular}

Fonte: Ministério de Minas e Energia (2006). 
Modelo de Mudanças Climáticas com Gastos

Públicos

\section{Quadro 4}

Evolução da Estrutura de Oferta de Energia

\begin{tabular}{lcccccc}
\hline \multirow{2}{*}{ Energia } & \multicolumn{2}{c}{ Brasil } & \multicolumn{2}{c}{ OCDE } & \multicolumn{2}{c}{ Mundo } \\
\cline { 2 - 7 } & $\mathbf{1 9 7 3}$ & $\mathbf{2 0 0 5}$ & $\mathbf{1 9 7 3}$ & $\mathbf{2 0 0 5}$ & $\mathbf{1 9 7 3}$ & $\mathbf{2 0 0 5}$ \\
\hline Petróleo e Derivados & $46,0 \%$ & $38,4 \%$ & $53,0 \%$ & $40,7 \%$ & $46,0 \%$ & $35,3 \%$ \\
Gás Natural & $0,4 \%$ & $9,3 \%$ & $18,8 \%$ & $22,0 \%$ & $15,9 \%$ & $20,9 \%$ \\
Carvão Mineral e Derivados & $3,1 \%$ & $6,4 \%$ & $22,4 \%$ & $20,5 \%$ & $24,3 \%$ & $24,1 \%$ \\
Urânio e Derivados & $0,0 \%$ & $1,2 \%$ & $1,3 \%$ & $10,7 \%$ & $0,9 \%$ & $6,4 \%$ \\
Energia Hidráulica e Eletricidade & $6,1 \%$ & $15,0 \%$ & $2,1 \%$ & $2,0 \%$ & $1,8 \%$ & $2,1 \%$ \\
Biomassa* & $44,8 \%$ & $29,7 \%$ & $2,5 \%$ & $4,0 \%$ & $11,0 \%$ & $11,2 \%$ \\
\hline
\end{tabular}

*Lenha, carvão vegetal, cana-de-açúcar, energia solar, eólica, geotérmica etc.

Fonte: Ministério de Minas e Energia (2006).

contra $13,3 \%$ do resto do mundo e $6 \%$ nos países da Organização para Cooperação e Desenvolvimento Econômico (OCDE) -, com $77 \%$ da energia elétrica vindo de usinas hidrelétricas, fonte relativamente mais limpa de energia. Contudo, a oferta de energia não renovável ainda é maior.

O Brasil tem investido e defendido nos fóruns internacionais o uso de energias renováveis, como o etanol da cana-de-açúcar e o biodiesel, que pode ser produzido a partir da soja, da mamona, do pinhão-manso, do girassol e do sebo animal. O país tem muito a contribuir e a usufruir com a ampliação de investimentos. No entanto, há ainda questões tecnológicas e comerciais. A tecnologia usada para produzir biocombustíveis pode ficar obsoleta rapidamente e muito do que se discute hoje para uso de biocombustível está relacionado a lobbies agrícolas, que podem favorecer subsídios que distorcem o comércio mundial e nem sempre estão preocupados com a redução da emissão de gases de efeito estufa.

Os biocombustíveis emitem menos destes gases que contribuem para o aquecimento do clima, mas tudo depende da maneira com a qual eles são produzidos. Hill et al. (2006) publicaram um texto na Proceedings of National Academy of Science (em português, Acade- 
mia Nacional de Ciências dos Estados Unidos) sobre a viabilidade econômica, ambiental e energética do etanol produzido por milho (método norte-americano) e do biodiesel produzido por soja. Os autores consideraram que, para um biocombustível ser viável, deveria fornecer: 1) ganho de energia (a energia fornecida deve ser maior que a energia consumida na produção); 2) benefícios ambientais; 3) competitividade econômica; e 4) produção em larga escala. O trabalho concluiu pela superioridade do biodiesel, mas ressaltou aspectos da inviabilidade atual de abastecimento generalizado do mercado.

O estudo foi realizado com base em etanol feito de milho, a produção por cana-de-açúcar produz muito mais energia do que consome. Friedman (2006) lembrou isso ao afirmar que o etanol por cana produz oito vezes mais energia do que gasta, enquanto o de milho produz apenas 1,3 vez mais. Caberia um estudo brasileiro para observar o impacto dos outros efeitos ambientais (uso de fertilizantes e florestais) da cana.

Sobre o principal acordo mundial de controle da mudança climática, o Protocolo de Quioto, os Estados Unidos e a Austrália ainda não o ratificaram. A argumentação recorrente destes países é a falta de metas para grandes emissores de gases de efeito estufa que não fazem parte do Anexo I do referido Protocolo, como a China (segundo maior poluidor) e o Brasil (considerado muitas vezes como quarto maior poluidor em fluxo de emissão). A China faz uso intensivo de carvão mineral para geração de energia. Avanços tecnológicos que permitissem o uso mais limpo do carvão ou o seqüestro do carbono emitido poderiam ser bastante benéficos para o controle climático. $\mathrm{Na}$ análise das emissões brasileiras, a observação pela metodologia de Uso do Solo e Manejo (em inglês, Land Use and Forestry), que observa a biomassa como fonte de energia e também as queimadas das florestas, mostra que o Brasil tem uma presença relevante nas emissões globais de gases. 
Modelo de Mudanças Climáticas com Gastos Públicos

Os países que não pertencem ao Anexo 1 contrapõem afirmando que a emissão de gases deles é pequena, em termos per capita. Se observarmos a população da China, não há como negar isso. Os Estados Unidos, que têm 5\% da população do planeta, são responsáveis por um quarto da emissão de gases de efeito estufa no mundo. Diamond (2005), inclusive, alerta que o mundo não seria capaz de fornecer energia para uma China com consumo per capita norte-americano.

Cabe observar, no entanto, que os efeitos da mudança climática são distribuídos no planeta. Por esse motivo, não há fronteiras para os efeitos de: aumento das áreas desérticas do planeta; maior evaporação de água; aumento dos insetos de clima quente que provocam doenças nos trópicos (malária e dengue, por exemplo); aumento do número de furacões, dado o aquecimento das águas dos oceanos; e perda de flora e fauna, especialmente daquelas mais dependentes de água, como os anfíbios. No Quadro 5, apresentamos a participação do consumo das diversas fontes de energia por habitante e por tamanho do território para Alemanha, Estados Unidos, Japão e BRIC.

A agência governamental norte-americana Energy Information Administration (EIA), em seu relatório de 2006 - International energy outlook 2006 (ENERGY INFORMATION ADMINISTRATION, 2006) -, considera que, mesmo observando as atuais exigências do Protocolo de Quioto, as emissões de dióxido de carbono no mundo provocadas pela queima de combustíveis fósseis devem atingir 33,7 bilhões de toneladas métricas em 2015 e 43,7 bilhões em 2030, sendo que as emissões de 1990 foram de 21 bilhões, com crescimento de $2,1 \%$ por ano de 2003 a 2030 do uso de combustíveis fósseis. 
Quadro 5

Consumo de Energia por Quilômetros Quadrados $\left(\mathrm{km}^{2}\right)$ e por Habitante - 2005

\begin{tabular}{lrrrrrrr}
\hline \multicolumn{1}{c}{ Consumo de Energia (por Habitante) } & Alemanha & EUA & Japão & Rússia & Brasil & China & Índia \\
\hline Consumo de Energia (m ton por m habitante) & 4,21 & 8,49 & 4,50 & 5,34 & 1,23 & 1,09 & 0,35 \\
Consumo Energia (kg oil por m habitante) & 50,97 & 28,73 & 35,31 & 37,22 & 6,78 & 0,83 & 0,32 \\
Consumo Eletricidade (bn kwh por m habitante) & 6,35 & 12,80 & 8,03 & 6,53 & 2,03 & 1,80 & 0,53 \\
Consumo Eletricidade (kwh per head por m habitante) & 76,88 & 43,28 & 63,03 & 45,51 & 11,18 & 1,38 & 0,49 \\
Consumo Petróleo (mil b/d por m habitante) & 32,15 & 68,25 & 41,53 & 19,43 & 11,89 & 5,44 & 2,32 \\
Consumo Carvão (m metric ton por m habitante) & 3,01 & 3,33 & 1,35 & 1,62 & 0,11 & 1,49 & 0,39 \\
Consumo Produtos Petróleo Refinado (mil b/d por m habitante) & 32,64 & 66,95 & 42,96 & $n . d$ & 12,58 & 6,10 & 2,29 \\
Consumo de Gás Natural (bn metros cub por m habitante) & 1,15 & 2,10 & 0,61 & 3,13 & 0,12 & 0,03 & 0,03 \\
\hline \multicolumn{1}{c}{ Consumo de Energia (por Quilômetros Quadrados) } & Alemanha & EUA & Japão & Rússia & Brasil & China & Índia \\
\hline Consumo de Energia (m ton por m KM ${ }^{2}$ ) & 0,97 & 0,26 & 1,52 & 0,04 & 0,03 & 0,15 & 0,12 \\
Consumo Energia (kg oil por m KM ${ }^{2}$ ) & 11,77 & 0,89 & 11,94 & 0,31 & 0,15 & 0,11 & 0,11 \\
Consumo Eletricidade (bn kwh por m KM ${ }^{2}$ ) & 1,46 & 0,40 & 2,72 & 0,05 & 0,04 & 0,25 & 0,18 \\
Consumo Eletricidade (kwh per head por m KM ${ }^{2}$ ) & 17,75 & 1,34 & 21,31 & 0,38 & 0,25 & 0,19 & 0,16 \\
Consumo Petróleo (mil b/d por m KM ${ }^{2}$ ) & 7,42 & 2,12 & 14,04 & 0,16 & 0,26 & 0,75 & 0,77 \\
Consumo Carvão (m metric ton por m KM ${ }^{2}$ ) & 0,69 & 0,10 & 0,46 & 0,01 & 0,00 & 0,20 & 0,13 \\
Consumo Produtos Petróleo Refinado (mil b/d por m KM ${ }^{2}$ ) & 7,54 & 2,07 & 14,53 & $n \cdot d$ & 0,28 & 0,84 & 0,77 \\
Consumo de Gás Natural (bn metros cub por KM ${ }^{2}$ ) & 0,26 & 0,07 & 0,21 & 0,03 & 0,00 & 0,00 & 0,01 \\
\hline \multicolumn{1}{c}{ Área em mil quilômetros quadrados } & 357,0 & $9.631,0$ & 377,0 & $17.075,0$ & $8.511,0$ & $9.590,0$ & $3.280,0$ \\
$\quad$ População em milhões & 82,4 & 298,4 & 127,5 & 142,9 & 188,1 & $1.314,0$ & $1.095,4$ \\
\hline
\end{tabular}

Fontes: Brazil... (2005), China... (2005), Germany ... (2006), India... (2006), Japan... (2005), Russia... (2005), USA... (2006) e Central Intelligence Agency (2006). 


\section{Gasto Público com Gestão Ambiental - Caso Brasileiro}

Neste item, apresento os gastos públicos federais no Brasil, na intenção de mostrar como eles permitem influenciar na redução de emissão de gases da mudança climática e quanto de seu orçamento a União destina ao meio ambiente.

O Artigo 23 da Constituição Federativa do Brasil (SENADO FEDERAL, 1988) estabelece que é competência comum da União, dos estados, do distrito federal e dos municípios: proteger o meio ambiente e combater a poluição em qualquer de suas formas (inciso VI); preservar as florestas, a fauna e a flora (inciso VII); proteger as paisagens naturais notáveis e sítios arqueológicos (inciso III); registrar, acompanhar e fiscalizar as concessões de direitos de pesquisa e exploração de recursos hídricos e minerais em seus territórios (inciso $\mathrm{XI}$ ); e promover programas de construção de saneamento básico (inciso IX).

Aqui, no entanto, a análise do gasto público em gestão ambiental será feita observando exclusivamente os gastos públicos federais. Analisamos as despesas alocadas para o Ministério do Meio Ambiente, depois consideramos as despesas com a função Gestão Ambiental e suas subfunções. O período de análise é de 2000 a 2006, porque foi a partir de 2000 que houve destaque para a função Gestão Ambiental no Demonstrativo da Execução das Despesas. Todos os dados têm como fonte o Relatório Resumido da Execução Orçamentária do Governo Federal e Outros Demonstrativos, de dezembro de 2006, que a Secretaria do Tesouro Nacional disponibiliza no seu site (SECRETARIA DO TESOURO NACIONAL, dez. 2006).

O Quadro 6 demonstra o valor das dotações e as liquidações do Ministério do Meio Ambiente (MMA), de 2000 a 2006, em valores no- 
Pedro Erik Arruda Carneiro

\section{Quadro 6}

Despesas Orçamentárias do Ministério do Meio Ambiente - R\$ mil

\begin{tabular}{lrrrr}
\hline \multicolumn{5}{c}{ Valores Nominais } \\
\hline Ano & Dotação Inicial & Dotação p/ Ano & Liquidação & Pagamento \\
\hline 2000 & $696.797,0$ & $861.565,0$ & $636.673,0$ & $552.454,0$ \\
2001 & $1.174 .232,0$ & $1.214 .328,0$ & $948.210,0$ & $948.210,0$ \\
2002 & $1.568 .229,0$ & $1.625 .035,0$ & $929.085,0$ & $763.293,0$ \\
2003 & $1.386 .813,0$ & $1.502 .517,0$ & $849.986,0$ & $771.556,0$ \\
2004 & $1.517 .519,0$ & $1.774 .172,0$ & $1.058 .618,0$ & $930.956,0$ \\
2005 & $2.136 .908,0$ & $2.244 .690,0$ & $1.112 .319,0$ & $1.007 .244,0$ \\
\hline \multicolumn{5}{c}{ Valores Reais (Novembro 2006) } \\
\hline Ano & Dotação Inicial Dotação p/ Ano & Liquidação & Pagamento \\
\hline 2000 & $1.141 .581,95$ & $1.411 .525,96$ & $1.043 .079,12$ & $905.100,79$ \\
2001 & $1.815 .323,44$ & $1.877 .310,51$ & $1.465 .900,98$ & $1.465 .900,98$ \\
2002 & $2.251 .654,28$ & $2.333 .216,01$ & $1.333 .974,96$ & $1.095 .931,75$ \\
2003 & $1.769 .459,03$ & $1.917 .087,80$ & $1.084 .512,05$ & $984.441,84$ \\
2004 & $1.771 .482,17$ & $2.071 .087,12$ & $1.235 .782,16$ & $1.086 .755,39$ \\
2005 & $2.318 .321,17$ & $2.435 .253,34$ & $1.206 .749,51$ & $1.092 .754,15$ \\
\hline
\end{tabular}

Fonte: Secretaria do Tesouro Nacional (dez. 2006).

minais e atualizados para novembro de 2006, pelo Índice de Preços ao Consumidor Amplo (IPCA) do IBGE.

Os valores demonstram que houve um período de queda acentuada na dotação inicial orçamentária para o MMA no ano de 2003, depois de ela ter obtido grandes saldos nos dois anos anteriores, recuperando-se mais fortemente, em termos reais, em 2005, para reduzir-se novamente em 2006. A despesa liquidada já caiu em 2002, e não foi recuperada, em termos reais, depois disto.

Comparada com a de outros órgãos, a despesa orçamentária do MMA é muito pequena. Entre os 37 órgãos do Demonstrativo das Despesas da União por Poder e Órgão, ${ }^{2}$ o MMA foi o $26^{\circ}$ em 2006 nas despesas liquidadas. Dentro do Poder Executivo, com 26 órgãos, o MMA foi o $20^{\circ}$ em 2006. No Gráfico 1, apresento a despesa liquidada em 2006 dos quinze últimos órgãos em despesa liquidada (1,7\% da despesa liquidada total), com destaque para a participação 
Modelo de Mudanças Climáticas com Gastos Públicos

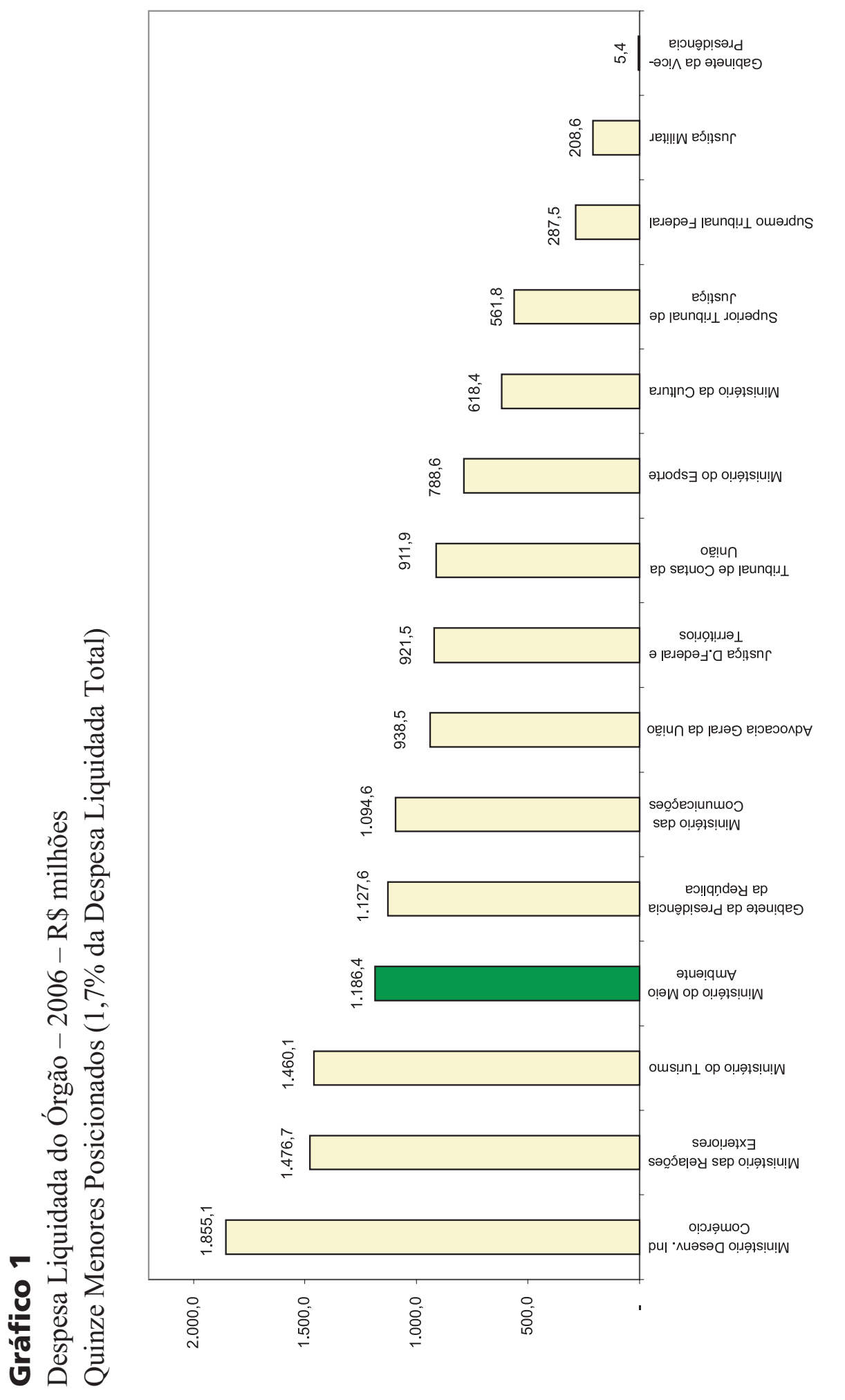


do MMA, que não ultrapassou $0,15 \%$ da despesa liquidada total em 2006, que foi de R $\$ 797,8$ bilhões. O MMA está atrás do Ministério das Relações Exteriores, do Ministério do Desenvolvimento e Comércio e do Gabinete da Presidência. Este resultado de 2006 não é atípico, aconteceu regularmente em todos os anos analisados, com pequenas variações na participação na dotação orçamentária dos ministérios.

\section{Quadro 7}

Participação na Despesa Liquidada Total (Excluindo Refinanciamento) 2000-2006

\begin{tabular}{lrrrrrrr}
\hline Função & $\mathbf{2 0 0 0}$ & $\mathbf{2 0 0 1}$ & $\mathbf{2 0 0 2}$ & $\mathbf{2 0 0 3}$ & $\mathbf{2 0 0 4}$ & $\mathbf{2 0 0 5}$ & $\mathbf{2 0 0 6}$ \\
\hline Encargos Especiais & $42,4 \%$ & $45,5 \%$ & $45,3 \%$ & $46,8 \%$ & $43,8 \%$ & $42,5 \%$ & $49,8 \%$ \\
Previdência Social & $29,6 \%$ & $28,1 \%$ & $28,1 \%$ & $29,5 \%$ & $30,4 \%$ & $31,1 \%$ & $26,4 \%$ \\
Saúde & $6,4 \%$ & $6,2 \%$ & $5,8 \%$ & $5,5 \%$ & $6,1 \%$ & $6,0 \%$ & $5,0 \%$ \\
Educação & $3,4 \%$ & $3,0 \%$ & $3,0 \%$ & $2,9 \%$ & $2,7 \%$ & $2,7 \%$ & $2,4 \%$ \\
Assistência Social & $1,4 \%$ & $1,4 \%$ & $1,5 \%$ & $1,7 \%$ & $2,5 \%$ & $2,6 \%$ & $2,7 \%$ \\
Defesa Nacional & $3,4 \%$ & $3,1 \%$ & $2,9 \%$ & $2,3 \%$ & $2,5 \%$ & $2,5 \%$ & $2,1 \%$ \\
Trabalho & $2,0 \%$ & $1,9 \%$ & $1,9 \%$ & $1,9 \%$ & $2,0 \%$ & $2,1 \%$ & $2,1 \%$ \\
Judiciária & $2,1 \%$ & $1,8 \%$ & $1,9 \%$ & $1,7 \%$ & $1,9 \%$ & $1,8 \%$ & $1,8 \%$ \\
Administração & $2,1 \%$ & $1,9 \%$ & $1,9 \%$ & $1,5 \%$ & $1,6 \%$ & $1,5 \%$ & $1,4 \%$ \\
Agricultura & $1,6 \%$ & $1,4 \%$ & $1,3 \%$ & $1,3 \%$ & $1,4 \%$ & $1,4 \%$ & $1,3 \%$ \\
Transporte & $1,0 \%$ & $1,0 \%$ & $1,2 \%$ & $0,6 \%$ & $0,7 \%$ & $1,1 \%$ & $0,9 \%$ \\
Legislativa & $0,6 \%$ & $0,6 \%$ & $0,6 \%$ & $0,6 \%$ & $0,7 \%$ & $0,6 \%$ & $0,6 \%$ \\
Organização Agrária & $0,3 \%$ & $0,3 \%$ & $0,3 \%$ & $0,3 \%$ & $0,5 \%$ & $0,6 \%$ & $0,5 \%$ \\
Ciência e Tecnologia & $0,4 \%$ & $0,4 \%$ & $0,3 \%$ & $0,4 \%$ & $0,5 \%$ & $0,5 \%$ & $0,5 \%$ \\
Segurança Pública & $0,7 \%$ & $0,7 \%$ & $0,5 \%$ & $0,5 \%$ & $0,5 \%$ & $0,5 \%$ & $0,5 \%$ \\
Comércio e Serviços & $0,6 \%$ & $0,7 \%$ & $0,4 \%$ & $0,4 \%$ & $0,4 \%$ & $0,5 \%$ & $0,3 \%$ \\
Essencial à Justiça & $0,2 \%$ & $0,2 \%$ & $0,2 \%$ & $0,3 \%$ & $0,4 \%$ & $0,4 \%$ & $0,4 \%$ \\
Urbanismo & $0,1 \%$ & $0,1 \%$ & $0,1 \%$ & $0,1 \%$ & $0,2 \%$ & $0,3 \%$ & $0,3 \%$ \\
Gestão Ambiental & $0,36 \%$ & $0,50 \%$ & $0,29 \%$ & $0,19 \%$ & $0,22 \%$ & $0,33 \%$ & $0,20 \%$ \\
Relações Exteriores & $0,2 \%$ & $0,2 \%$ & $0,3 \%$ & $0,2 \%$ & $0,2 \%$ & $0,3 \%$ & $0,2 \%$ \\
Indústria & $0,1 \%$ & $0,1 \%$ & $0,1 \%$ & $0,1 \%$ & $0,3 \%$ & $0,2 \%$ & $0,3 \%$ \\
Direitos da Cidadania & $0,1 \%$ & $0,2 \%$ & $0,1 \%$ & $0,1 \%$ & $0,1 \%$ & $0,1 \%$ & $0,1 \%$ \\
Habitação & $0,5 \%$ & $0,1 \%$ & $0,0 \%$ & $0,0 \%$ & $0,1 \%$ & $0,1 \%$ & $0,1 \%$ \\
Cultura & $0,1 \%$ & $0,1 \%$ & $0,1 \%$ & $0,0 \%$ & $0,1 \%$ & $0,1 \%$ & $0,1 \%$ \\
Comunicações & $0,1 \%$ & $0,1 \%$ & $0,1 \%$ & $0,1 \%$ & $0,1 \%$ & $0,1 \%$ & $0,1 \%$ \\
Energia & $0,2 \%$ & $0,2 \%$ & $1,8 \%$ & $0,8 \%$ & $0,1 \%$ & $0,1 \%$ & $0,1 \%$ \\
Desporto e Lazer & $0,1 \%$ & $0,1 \%$ & $0,1 \%$ & $0,0 \%$ & $0,0 \%$ & $0,1 \%$ & $0,1 \%$ \\
Saneamento & $0,1 \%$ & $0,1 \%$ & $0,0 \%$ & $0,0 \%$ & $0,0 \%$ & $0,0 \%$ & $0,0 \%$ \\
\hline SUBTOTAL & $100,0 \%$ & $100,0 \%$ & $100,0 \%$ & $100,0 \%$ & $100,0 \%$ & $100,0 \%$ & $100,0 \%$ \\
\hline & & & & & & &
\end{tabular}

Fonte: Secretaria do Tesouro Nacional (dez. 2006). 
Modelo de Mudanças Climáticas com Gastos Públicos

Passo agora a uma análise sob o ponto de vista da classificação funcional, observando a participação da função Gestão Ambiental nas despesas federais no Quadro 7 e, em seguida, consideramos as subfunções. Para esta análise, excluímos a função Encargos Especiais Refinanciamento, uma vez que essa despesa se refere à rolagem das dívidas públicas interna e externa e não ao desembolso com juros e amortização.

Podemos observar, acima, que 44,4\%, em média, da despesa por função é de Encargos Especiais e 29,5\%, em média, é de Previdência, somando 73,8\% com essas duas funções. É na disputa de $26,2 \%$ da despesa federal que a Gestão Ambiental se posiciona, junto com despesas com Educação, Saúde, Segurança Pública, Habitação etc. Em média, a Gestão Ambiental tem $0,31 \%$ da despesa liquidada federal de 2000 a 2006.

Quando observamos as subfunções da Gestão Ambiental no período 2000 a 2006, vemos que há bastante instabilidade na alocação dos recursos orçamentários entre as subfunções, o que pode prejudicar a continuidade dos esforços em alguns setores ambientais. No entanto, pode-se dizer que há uma ênfase em Recursos Hídricos; Administração Geral; Preservação, Conservação e Controle Ambiental. Aqui não apresento ano a ano as despesas liquidadas para cada subfunção, mas, para deixar claro essa instabilidade, mostramos no Quadro 8 a alocação entre os anos 2004 e 2005, quando houve uma mudança mais radical nas subfunções. Para os anos anteriores a 2004, as variações são mais relacionadas à distribuição de recursos entre as subfunções, apesar de também contarem com exclusão e introdução de subfunções.

Vemos, acima, que em 2004 a subfunção Administração Geral superou a de Recursos Hídricos em mais do dobro, como subfunção de maior liquidação. Esse fato foi compensado em 2005. A subfunção Reforma Agrária, incluída apenas em 2005, ficou bem posicionada 
Quadro 8

Subfunções da Gestão Ambiental 2004-2005 - R\$ mil

\begin{tabular}{lr|lr}
\hline Subfunções 2004 da Gestão Ambiental & Liquidação 2004 & Subfunções 2005 da Gestão Ambiental & Liquidação 2005 \\
\hline Administração Geral & $629.349,00$ & Recursos Hídricos & $1.022 .570,0$ \\
Recursos Hídricos & $307.567,00$ & Administração Geral & $645.575,0$ \\
Preservação e Conserv. Ambiental & $86.567,00$ & Preservação e Conservação Ambiental & $111.194,0$ \\
Outros Encargos Especiais & $40.153,00$ & Controle Ambiental & $43.043,0$ \\
Controle Ambiental & $35.482,00$ & Reforma Agrária & $38.265,0$ \\
Normatização e Fiscalização & $33.656,00$ & Normatização e Fiscalização & $29.184,0$ \\
Recuperação de Áreas Degradadas & $13.198,00$ & Recuperação de Áreas Degradadas & $20.566,0$ \\
Atenção Básica & $9.199,00$ & Formação de Recursos Humanos & $13.834,0$ \\
Alimentação e Nutrição & $8.920,00$ & Alimentação e Nutrição & $11.865,0$ \\
Tecnologia da Informação & $7.221,00$ & Atenção Básica & $11.352,0$ \\
Formação de Recursos Humanos & $6.260,00$ & Tecnologia da Informação & $11.157,0$ \\
Planejamento e Orçamento & $5.692,00$ & Promoção de Produção Vegetal & $5.961,0$ \\
Difusão Conhecimento Cient. e Tecn. & $3.542,00$ & Difusão do Conhecimento Cient. e Tecn. & $5.454,0$ \\
Proteção e Benef. ao Trabalhador & $1.476,00$ & Saneamento Básico Rural & $5.345,0$ \\
Educação Infantil & $1.196,00$ & Planejamento e Orçamento & $4.914,0$ \\
Transferência & $1.157,00$ & Cooperação Internacional & $2.975,0$ \\
Desenvolvimento Tecn. e Engenharia & 527,00 & Proteção e Benefícios ao Trabalhador & $1.509,0$ \\
Promoção de Produção Vegetal & 523,00 & Ordenamento Territorial & $1.267,0$ \\
Comunicação Social & 454,00 & Educação Infantil & $1.194,0$ \\
\hline
\end{tabular}




\section{Quadro 8}

Subfunções da Gestão Ambiental 2004-2005 - R\$ mil

(continuação)

\section{Subfunções 2004 da Gestão Ambiental}

Patrimônio Histór., Artíst. e Arqueológico

Desenvolvimento Científico

Ordenamento Territorial

Extensão Rural

Assistência Comunitária

Difusão Cultural

Saneamento Básico Urbano

\section{Liquidação 2004 Subfunções 2005 da Gestão Ambiental}

401,00 Difusão Cultura

377,00 Desenvolvimento Científico

333,00 Patrimônio Histórico, Artístico e Arqueológico

194,00 Comunicação Social

$\begin{array}{ll}0,00 \text { Turismo } & 591,0\end{array}$

0,00 Saneamento Básico Urbano $\quad 525,0$

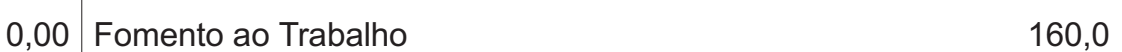

Desenvolvimento Tecn. e Engenharia $\quad 97,0$

Extensão Rural $\quad 79,0$

Policiamento $\quad 0,0$

Assistência aos Povos Indígenas

0,0

\begin{tabular}{lr|lr}
\hline Total & $1.193 .444,00$ & Total & $1.992 .007,00$ \\
\hline Média & $45.901,69$ & Média & $76.608,88$ \\
\hline
\end{tabular}

Fonte: Secretaria do Tesouro Nacional (dez. 2006). 
nas Despesas Liquidadas (quinta posição). Apesar da volta da Assistência aos Povos Indígenas e da inclusão de Policiamento (que faziam parte antes de 2004), essas duas subfunções não tiveram nenhuma despesa liquidada em 2005.

Apesar da instabilidade e da falta de recursos aplicados no Brasil para a Gestão Ambiental, podemos observar no Quadro 8 que diversas subfunções permitem redução de emissão de gases poluentes, com destaque para a Preservação e Conservação Ambiental, Recuperação de Áreas Degradadas, Recursos Hídricos e Saneamento Básico Rural. Entre os países, a alocação e distribuição de recursos são, obviamente, bastante variadas, dadas as estruturas físicas e econômicas de cada um. A seguir, observamos a possível inserção desses gastos públicos em modelos de mudança climática.

\section{Modelo de Redução de Emissão com Gastos Públicos}

Depois de apresentar o modelo de Kemfert, Lise e Tol (2004), os diferentes riscos ao meio ambiente no Brasil, as diferenças entre as matrizes energéticas dos países, e de analisar os gastos públicos federais brasileiros com gestão ambiental, nesta seção, procuro agregar o que foi discutido em uma análise de um possível modelo que considera os gastos públicos para redução de emissão de gases de efeito estufa.

Qualquer modelo reduz a realidade e não tem a pretensão de dar uma resposta definitiva. No caso do modelo de Kemfert, Lise e Tol (2004), nem se chega a uma resposta ampla, mas mesmo assim é muito relevante pelo poder de análise.

Um estudo sobre mudança climática requer análise bastante complexa pela exigência de abordagem multidisciplinar e porque muitas vezes nos perguntamos que variável vem antes da outra. Há dúvida na 
formulação de um modelo, por exemplo, quanto ao que vem primeiro: os termos de troca, a matriz energética ou os gastos públicos com gestão ambiental.

Vamos imaginar que, em vez de seguirmos Kemfert, Lise e Tol (2004), que fazem uma análise de custo e benefício, elaboramos uma análise baseada na minimização da emissão de gases de efeito estufa em relação aos gastos públicos com gestão ambiental, tentando agregar, mais explicitamente, os termos de troca e a matriz energética.

Consideremos que a emissão é função de: 1) porcentagem de energia renovável na matriz energética $(m)$, pois um país pode estabelecer tanto uma matriz centrada em carvão mineral, a mais poluente, como em energia eólica, de emissão zero; e 2) termos de troca, representados pela taxa de crescimento dos preços relativos $\left(p_{i}-p_{j}\right)$, sendo $p_{i}$ a taxa de crescimento dos bens domésticos transacionáveis, e $p_{j}$, a taxa de crescimento dos preços dos bens externos transacionáveis.

Vamos supor que tanto $m$ quanto $p_{i}$ são função dos gastos públicos. Temos, para o nível de emissão real:

$E_{i}^{R}=f\left(m_{i}\left(G_{i}\right)\right)+k_{i}\left(p_{i}\left(G_{i}\right)-p_{i}\right)$

Sendo:

$$
\begin{aligned}
& m_{i}(0)=0, x \mathrm{f} 0 \rightarrow m_{i}(x) \mathrm{f} 0, \frac{\partial m_{i}}{\partial x} \mathrm{f} 0, \frac{\partial^{2} m_{i}}{\partial x^{2}} \mathrm{f} 0 \\
& f_{i}(0)=0, x \mathrm{f} 0 \rightarrow f_{i}(x) \mathrm{p} 0, \frac{\partial f_{i}}{\partial x} \mathrm{p} 0, \frac{\partial^{2} f_{i}}{\partial x^{2}} \mathrm{p} 0
\end{aligned}
$$

Para 11, considero que os gastos públicos em gestão ambiental serão no sentido de aumentar a porcentagem de energia renovável. Em 12, mostro que o impacto de $m$ será na direção de reduzir a emissão de gases poluentes. 
Fica faltando analisar $k_{i}($. $)$ e $p_{i}\left(G_{i}\right)$. Poderíamos supor para $k_{i}($.$) que,$ quanto maior a taxa de crescimento dos preços dos bens domésticos em relação aos preços dos bens externos, maior a emissão. Para $p_{i}$ $\left(G_{i}\right)$, suponho que os gastos públicos reduzem a necessidade de redução de emissão pelas firmas e ampliam a produção de energia renovável.

No entanto, como Kemfert, Lise e Tol (2004, p. 212) observaram: "Uso de energia mais cara em um país simplesmente mudará os termos de troca, para melhor ou pior”. A redução de emissão altera os termos de troca, mas não se sabe, de forma generalizada, o impacto nos preços dos bens domésticos em relação aos bens externos.

Além da dificuldade de análise de $k_{i}\left(\right.$.) e $p_{i}\left(G_{i}\right)$, podemos argumentar, com foco na política fiscal, que os gastos públicos é que são função dos termos de troca e da matriz energética, e não o contrário, pois esses gastos são financiados pela produção da economia, na qual os termos de troca e a matriz energética são variáveis formadoras. Assim, passamos a discutir quem vem primeiro.

Olhando também o modelo de Kemfert, Lise e Tol (2004) e suas considerações, há muitos ângulos possíveis em que pode ser vista a questão da redução de emissão de gases de mudança climática. Por exemplo, observando a equação (1) do custo de emissão, no que se refere à função $f($.), a redução de emissão tem impacto nos preços dos bens intensivos em energia, mas também em outros bens por consequiência, e assim afetaria, em certa magnitude, a taxa de desemprego da economia, com resultado, normalmente, adverso sobre o PIB, elevando a razão $\frac{C}{Y}$. A função $g($.) também tem efeito controverso. A redução de emissão em um país pode provocar elevação do desemprego, o que pode reduzir os preços da mão-de-obra, tendo efeitos positivos sobre o comércio internacional do país, e incentivar investimentos em bens não intensivos em energia. Em outras palavras, temos dois 
efeitos conflitantes: efeito preço, que piora os termos de troca da balança comercial, e o efeito renda do trabalho, que melhora. O impacto de $h($.), pela simples razão de ser função de $C$, é também ambíguo. Neste sentido, o modelo é ainda bastante frágil nas suas considerações, e o resultado identificado de não-conclusão acaba salvando o artigo, pois prova que as diversas interações provocadas pela redução de emissão tornam bastante complexas as análises por meio de um modelo formal.

A introdução dos gastos públicos no modelo de Kemfert, Lise e Tol (2004) incrementa ainda mais as possibilidades. Podemos considerar a seguinte formulação para o custo de redução de emissão:

$\frac{C_{i}}{Y_{i}}=\frac{C_{i}\left(R_{i}, R_{j}, G_{i}, C_{i}\right.}{Y_{i}}=f\left(R,\left(G_{i}\right)\right)+g_{i}\left(R\left(G_{i}\right)_{i}-R_{i}\right)+h_{i}\left(C_{i}\right)$

Quais seriam as justificativas para esta formulação? Ora, supõe-se que a redução de emissão é dependente dos gastos públicos em termos domésticos, pois um país irá realizar uma política de redução de emissão observando sua condição físcal. Além disso, a seção 4 mostrou que os gastos públicos com gestão ambiental têm impacto sobre os gases de mudança climática. Por exemplo, a preservação da floresta nativa - evitando que ela se queime, transformando-se em gás carbônico, ou se apodreça em líquido, transformando-se em metano - tem claro efeito sobre a redução de emissão de gases. Os gastos públicos com gestão ambiental no Brasil mostraram uma prevalência da preocupação com os recursos hídricos que também têm forte relação com os efeitos da mudança climática.

Em termos gerais, no entanto, a análise dos resultados dos modelos ficaria prejudicada, porque estamos supondo que a elevação dos gastos públicos com gestão ambiental seria benéfica para o país, reduzindo a emissão de gases de efeito estufa sem trazer prejuízos para os termos de troca, isto é, sem elevação dos preços intensivos em ener- 
gia. Poderíamos imaginar também que os gastos públicos deveriam ser função dos termos de troca, que são função da redução de emissão.

Sabemos que há limites para que o impacto dos gastos públicos nos termos de troca não ocorra e, além disso, há diferenças de limites entre os países. Observando o caso brasileiro, uma maior fiscalização e punição efetiva para o desmatamento, evitando a emissão de gases por queimadas, talvez fosse bem indolor aos termos de troca, mas muitos países não têm essa possibilidade. Se considerarmos que os gastos públicos com gestão ambiental podem afetar também, por ação ou por omissão, a matriz energética, por exemplo, por meio da preservação dos recursos hídricos para hidrelétricas, a possibilidade de análise variará bastante.

Também é óbvio que a distribuição dos gastos públicos está intimamente relacionada com a capacidade de tributação do ente estatal. O sistema tributário adotado tem impacto sobre as escolhas do setor produtivo e sobre a matriz energética. O próprio uso de uma tributação que promova a redução de emissão é um tipo de gasto público, na medida em que se abdica de método de arrecadação já reconhecido e aceito pelos contribuintes. Há também limites políticos e econômicos para o incremento na arrecadação para que se promova a redução de emissão.

Em suma, destaco, principalmente, que não se pode avaliar o custo da redução de emissão, sem se observar a importância de gastos públicos com gestão ambiental, pois estes gastos levarão em consideração a estrutura física ambiental, as demandas públicas, a matriz energética do país e irão contribuir para a redução de emissão de gases poluentes. Sobre como fazer a inclusão, entendo, no entanto, que há ainda bastante dificuldade.

A análise de políticas de controle da mudança climática por meio de modelos formais é sempre muito importante, pois facilita a compre- 
Modelo de Mudanças Climáticas com Gastos Públicos

ensão das interações econômicas que envolvem essas políticas. Aqui, todavia, observo que ainda há dificuldade de se adicionar, em um modelo, algumas importantes relações econômicas, que envolvem o mercado e o ente público, para redução de emissão. Também ressalto a necessidade de se observar as condições diversas dos países no momento da elaboração de análise econômica da mudança climática.

\section{Conclusão}

A não-identificação da existência de um trabalho relevante, que tentasse reunir gastos públicos com gestão ambiental e as questões relativas à mudança climática e que mostrasse como esses gastos podem incentivar e ampliar as possibilidades de controle dos gases de efeito estufa, foi a primeira motivação deste trabalho. Geralmente, é dito que os governos dispõem de dois tipos de instrumentos: multar quem não segue os princípios ambientalmente responsáveis e incentivar aqueles que os seguem. No entanto, tem-se abandonado os gastos públicos como método mais elementar para lidar com mudança climática.

Inicialmente, para introduzir a discussão de análises que agregam questões climáticas com restrições econômicas, apresentamos o modelo de Kemfert, Lise e Tol (2004). Neste modelo, os autores buscaram a redução ótima de emissão, observando, especialmente, os termos de troca. Os autores, no final, defendem que, considerando apenas um modelo formal, não é possível dizer se os efeitos de transbordamento levarão a maiores ou menores reduções de emissão, maiores ou menores custos de redução e, assim, se os efeitos sobre o comércio ajudarão ou prejudicarão a cooperação internacional para redução de emissão de gases poluentes. A resposta depende da força relativa de vários efeitos. A análise do modelo serviu, no entanto, para mostrar as dificuldades de estudos que tentam reunir mudança climática com questões econômicas. 
Depois, para cimentar a argumentação de que os gastos públicos com gestão ambiental atuam sobre diferentes perspectivas no mundo, mostrei as diferentes formas de impacto ambiental e as diferenças entre as matrizes energéticas dos países. Em termos das formas de impacto ambiental, cada país tem a sua porção, muitas vezes grande, dos doze processos ambientais de Diamond (2005): o caso brasileiro está bem explícito no Suplemento meio ambiente 2002, do IBGE (2005).

Sobre a matriz energética, há questões sobre a capacidade do meio ambiente em absorver a demanda crescente de energia mundial, uma vez que há dificuldades de adoção de alternativas tecnológicas de energia e alto grau de dependência do uso de combustível fóssil (carvão mineral, petróleo ou gás natural) que não é renovável e provoca emissão de gases nocivos ao planeta. Vimos que, entre os países, há bastantes diferenças no consumo e na produção de energia. O Brasil destaca-se pela produção de energia renovável e pela chance de ser um grande fornecedor de etanol, mas esta produção não está isenta de impacto ambiental.

$\mathrm{Na}$ análise do caso brasileiro para os gastos públicos federais com gestão ambiental, podemos perceber primeiro a pequena magnitude que foi alocada para estes gastos no período de 2000 a 2006, sofrendo, inclusive, os dissabores de condições macroeconômicas ruins dos anos de 2002 e 2003. Além disso, há a assimetria na alocação dos recursos entre os ministérios e entre as funções do orçamento brasileiro. Considerando os 26 órgãos do Poder Executivo, o Ministério do Meio Ambiente foi o vigésimo em despesas liquidadas em 2006. Este ministério está entre os quinze menores orçamentos no período de 2000 a 2006, com despesa liquidada por volta de $0,15 \%$ da despesa liquidada total.

A função Gestão Ambiental teve de disputar, em média, 26,2\% das despesas liquidadas, de 2000 a 2006, junto com as demandas para 
Modelo de Mudanças Climáticas com Gastos Públicos

educação, saúde, moradia e segurança pública. Em média, a Gestão Ambiental ficou com 0,31\% da despesa liquidada federal, excluindo refinanciamento, de 2000 a 2006. As subfunções mostram-se bastante instáveis em termos de alocação de recursos, mas há especial ênfase em Recursos Hídricos, Administração Geral e Preservação, Conservação e Controle Ambiental.

Apesar da instabilidade e da falta de recursos aplicados no Brasil para a Gestão Ambiental, observei que diversas subfunções permitem redução de emissão de gases de mudança climática. Também lembrei que, entre os países, a alocação e distribuição de recursos são variadas, dadas as estruturas físicas e econômicas de cada um.

Depois de apresentar as diferenças entre matrizes energéticas, impactos ambientais e dar um exemplo de distribuição dos gastos públicos com gestão ambiental, com o caso brasileiro, passei a considerar a introdução destes gastos em um modelo formal.

Inicialmente, observei um possível modelo de minimização da emissão de gases de efeito estufa em relação aos gastos públicos com gestão ambiental, tentando agregar, mais explicitamente, os termos de troca e a matriz energética. Considerei que a emissão é função da porcentagem de energia renovável na matriz energética $(m)$ e dos termos de troca, sendo que tanto esta porcentagem, quanto a taxa de crescimento dos preços dos bens transacionáveis são função dos gastos públicos com gestão ambiental.

Mostrei que, nessa abordagem, tive a mesma dificuldade de Kemfert, Lise e Tol (2004), que observaram que uso de energia mais cara em um país simplesmente mudará os termos de troca, para melhor ou pior. Além disso, poderíamos supor que os gastos públicos refletem os termos de troca e a matriz energética de um país, e não o contrário, pois estes gastos são financiados pela produção da economia, na qual os termos de troca e a matriz energética são variáveis formadoras. Assim, passaríamos a discutir quem vem primeiro. 
Em seguida, analisei uma ampliação do modelo de Kemfert, Lise e Tol (2004) e novamente percebi que os dilemas do modelo permanecem e se incrementam com a introdução dos gastos públicos com gestão ambiental.

Este artigo, em suma, pretende argumentar que não se pode avaliar o custo de redução de emissão, sem considerar a necessidade de gastos públicos com gestão ambiental, pois estes gastos levarão em consideração a estrutura física ambiental, as demandas públicas, a matriz energética do país e irão contribuir com a redução de emissão de gases poluentes. No entanto, a inclusão em modelos formais é bastante complexa. Há ainda dificuldade de se adicionar, em um modelo, algumas importantes relações econômicas, que envolvem o mercado e o ente público, para redução de emissão de gases que provocam mudança climática, tendo em mente as condições econômicas e físicas diversas dos países no momento da elaboração da análise econômica.

\section{Notas}

1. Esta e as demais citações de textos originalmente escritos em língua estrangeira foram livremente traduzidas para este artigo.

2. Disponível em: <http://www.stn.fazenda.gov.br/contabilidadeãgovernamental/gestao_orcamentaria.asp>. Acesso em: 25 out. 2007. 
BRAZIL: energy and electricity forecast. The Economist Intelligence Unit, 9 ago. 2005. Disponível em: <http://www.viewswire.com>. [Com subscrição]. Acesso em: 31 out. 2007.

CENTRAL INTELLIGENCE AGENCY. The World Factbook 2006. Disponível em: <https://www.cia.gov/library/publications/the-world-factbook/>. Acesso em: 31 out. 2007.

CHINA: energy and electricity forecast. The Economist Intelligence Unit, 24 out. 2005. Disponível em: <http://www.viewswire.com>. [Com subscrição]. Acesso em: 31 out. 2007.

CHINA economy: a dirty dragon? The Economist Intelligence Unit, 8 mai. 2007. Disponível em: <http://www.viewswire.com>. [Com subscrição]. Acesso em: 25 out. 2007.

COLEÇÃO FOLHA - Grandes Mestres da Pintura. Leonardo da Vinci, n. 3. Barueri: Folha de S. Paulo, 2007.

DIAMOND, Jared. Colapso: como as sociedades escolhem o fracasso ou o sucesso. Rio de Janeiro: Editora Record, 2005.

ENERGY INFORMATION ADMINISTRATION. International energy outlook 2006. Washington, DC: EIA, jun. 2006.

FRIEDMAN, Thomas. A estupidez americana. Folha de S. Paulo, 21 set. 2006.

FULLERTON, Don; STAVINS, Robert. How economists see the environment. Nature, v. 395, 1ํout. 1998.

GERMANY: energy and electricity forecast. The Economist Intelligence Unit, 1 mar. 2006. Disponível em: <http://www.viewswire.com>. [Com subscrição]. Acesso em: 31 out. 2007.

GOULDER, Lawrence H.; PIZER, William A. The economics of climate change. National Bureau of Economic Research, Cambridge, MA, n. w11923, jan. 2006. 
HILL, Jason; NELSON, Erik; TILMAN, David; POLASKY, Stephen; TIFFANY, Douglas. Environmental, economic and energetic costs and benefits of biodiesel and ethanol biofuels. Proceedings of National Academy of Science, v. 103, n. 30, jul. 2006.

IBAMA. Geo Brasil 2002 - perspectivas do meio ambiente no Brasil. Brasília: IBAMA, 2002. Disponível em: <http://ibama2.ibama.gov.br/cnia2/download-nao-vale/publicacoes/geobr/geobrasil-pdf.htm>. Acesso em: 31 out. 2007.

IBGE. Pesquisa de informações básicas municipais. Perfil dos municípios brasileiros. Suplemento Meio Ambiente 2002. Rio de Janeiro: IBGE, 2005.

INDIA: energy and electricity forecast. The Economist Intelligence Unit, 2 mar. 2006. Disponível em: <http://www.viewswire.com>. [Com subscrição]. Acesso em: 31 out. 2007.

JAPAN: energy and electricity forecast. The Economist Intelligence Unit, 30 nov. 2005. Disponível em: <http://www.viewswire.com>. [Com subscrição]. Acesso em: 31 out. 2007.

KEMFERT, Claudia; LISE, Wietze; TOL, Richard S. J. Games of climate with international trade. Environmental and Resource Economics, v. 28, n. 2, p. 209-232, 2004.

LANGE, Andreas; VOGT, Carsten. Cooperation in international environmental negotiations due to a preference for equity. Journal of Public Economics, v. 87, n. 9-10, p. 2.049-2.067, 2003.

MINISTÉRIO DE MINAS E ENERGIA. Balanço energético nacional de 2005. Brasília: MME, 2006. Disponível em: <http://www.mme.gov.br/site/menu/select_main_menu_item.do?channelId=1432>. Acesso em: 25 out. 2007.

NORDHAUS, William. How fast should we graze the global commons? The American Economic Review, v. 72, n. 2, p. 242-246, mai. 1982.

Life after Kyoto. National Bureau of Economic Research, Cambridge, MA, n. w11889, dez. 2005.

RUSSIA: energy and electricity forecast. The Economist Intelligence Unit, 14 jul. 2005. Disponível em: <http://www.viewswire.com>. [Com subscrição]. Acesso em: 31 out. 2007.

SECRETARIA DO TESOURO NACIONAL. Relatório Resumido da Execução Orçamentária do Governo Federal e Outros Demonstrativos. Brasília: Mi- 
Modelo de Mudanças Climáticas com Gastos

Públicos

nistério da Fazenda, dez. 2006. Disponível em: <http://www.stn.fazenda.gov.br/hp/downloads/lei_responsabilidade/RROdez2006.pdf $>$. Acesso em: 31 out. 2007.

SENADO FEDERAL. Constituição da República Federativa do Brasil, 1988. Disponível em: <http://www.senado.gov.br/sf/legislacao/const/>. Acesso em: 31 out. 2007.

USA: energy and electricity forecast. The Economist Intelligence Unit, 18 abr. 2006. Disponível em: <http://www.viewswire.com>. [Com subscrição]. Acesso em: 31 out. 2007.

WORLD oil outlook. The Economist Intelligence Unit, abr. 2007. Disponível em: <http://www.viewswire.com>. [Com subscrição]. Acesso em: 31 out. 2007.

\section{Resumo}

\section{Modelo de Mudanças Climáticas com Gastos Públicos}

Neste artigo, discuto, principalmente, a inserção dos gastos públicos em modelos de mudança climática. Considero a análise de Kemfert, Lise e Tol (2004) como exemplo de modelo formal que agrega as questões econômicas e climáticas, e amplio a discussão com o estudo da inserção dos gastos públicos com gestão ambiental e da matriz energética. Mostro que as estruturas econômicas e físicas dos países estabelecem diferentes gastos públicos, com diferentes impactos ambientais e conseqüências para outras nações e isto afeta sobremaneira os resultados de qualquer modelo econômico. Em termos dos gastos públicos com meio ambiente, observo especificamente o caso brasileiro, verificando os gastos públicos federais com Gestão Ambiental no Brasil de 2000 a 2006. Defendo a importância de se considerar as diversas possibilidades de despesas públicas com gestão ambiental, para o tratamento das questões relativas à mudança climática. 
Palavras-chave: Gasto Público Federal com Gestão Ambiental - Matriz Energética Mundial - Mudança Climática - Aquecimento Global

\section{Abstract}

\section{Climate Change Models with Public Spending}

In this paper, I, mainly, analyzed the inclusion of environmental budget in climate change models. Considering Kemfert, Lise and Tol (2004)'s approach to show a formal model that puts together economic and climate issues, I analyzed the inclusion of environmental public spending and energy. I tried to show that countries' economic and physical structures establish different public spending, with different environmental impacts and consequences to another nations and that has strong influence on economic models. In relation to public spending, I considered, specifically, the Brazilian federal budget to Environmental Management from 2000 to 2006. In this article, I argue in defense of considering budget for environmental management in the discussion on climate change

Keywords: Environmental Brazilian Federal Budget - World Energy Climate Change - Global Warming 